\title{
Development and Optimization of Insulin-Chitosan Nanoparticles
}

\author{
Liang Zhao ${ }^{1^{*}}$, Chang $\mathrm{Su}^{2^{*}}$, Bingya $\mathrm{Zhu}^{1}$ and Yunhong $\mathrm{Jia}^{1}$ \\ ${ }^{1}$ College of Pharmacy, ${ }^{2}$ College of Veterinary Medicine, Liaoning Medical University, Jinzhou 121000, Liaoning Province, \\ China.
}

*For correspondence: Email: lypharmacy@/63.com; Tel: +86-15804168627; Fax: +86-04164673320

\begin{abstract}
Purpose: To optimize the preparation of insulin-chitosan nanoparticles (ICNS) using response surface methodology (RSM).

Methods: ICNS were formulated through ionic cross linking method. The effects of the ratio between insulin and chitosan, $\mathrm{pH}$ of the medium and rotation speed on insulin encapsulation efficiency (EE) were investigated. Box-Behnken experimental design coupled with response surface method was employed to optimize formulation. Properties such as particle shape, size, zeta potential and release behavior were analyzed.

Results: The best formulation was produced under the following conditions: the ratio between insulin and chitosan was $0.08, \mathrm{pH} 3.0$, and rotation speed $187.4 \mathrm{rpm}$. Verifying experiments were established under the optimal conditions and EE was $93.1 \%$. Nanoparticles showed fine degree of sphericity and homogenous distribution of particle size. The particle size of nanoparticles was between $91.3 \pm 7.9$ and $220.2 \pm 9.5 \mathrm{~nm}$ and the average zeta potential was $14.4 \pm 2.9 \mathrm{mv}$. More than $16.8 \%$ of total drug was released rapidly in the first $1 \mathrm{~h}$. Thereafter, the insulin trapped in ICNS was released into the medium slowly and $>93.0 \%$ was released completely within $24 \mathrm{~h}$. Ritger-Peppas model was the best-fit drug release from all the formulations. The diffusion exponent $(n)$ indicates that drug release pattern was non-Fickian diffusion.

Conclusion: Response surface method was a useful tool to predict the optimal formulation. ICNS showed excellent characteristics of homogenous particle size distribution, good spherical property, positive zeta potential and longer drug delivery. It could be a promising carrier for the oral administration of insulin.

Keywords: Nanoparticles, Response surface methodology, Insulim release, Encapsulation efficiency, Zeta potential, Ritger-Peppas model, Box-Behnken design.

Tropical Journal of Pharmaceutical Research is indexed by Science Citation Index (SciSearch), Scopus, International Pharmaceutical Abstract, Chemical Abstracts, Embase, Index Copernicus, EBSCO, African Index Medicus, JournalSeek, Journal Citation Reports/Science Edition, Directory of Open Access Journals (DOAJ), African Journal Online, Bioline International, Open-J-Gate and Pharmacy Abstracts
\end{abstract}

\section{INTRODUCTION}

Research on insulin in the management of diabetes mellitus and its preparations is still attracting increasing attention. Researchers tend to design a variety of insulin formulations based on drug delivery theory as a foundation and after a thorough research on physico-chemical properties in vitro and in vivo pharmacodynamics. Insulin formulations for oral delivery are emulsions [1], liposomes [2], microspheres [3] and nanoparticles [4]. Nanoparticles, as a drug delivery system, have become an excellent oral insulin delivery carrier [5]. Research shows that nanoparticles produced intestinal uptake in $M$ cells and transport across membrane in the intestinal villi positions. When the small intestinal epithelial cells and Cells which had similar functions with $\mathrm{M}$ cells were co-cultured in vitro, transport velocity of polystyrene particles with 200 and $500 \mathrm{~nm}$ were increased 200-fold [6]. 
Chitosan (CS) as the only alkalescent polysaccharide in nature has a good biocompatibility, biodegradability, adhesion and non-toxicity and has been widely used in medical and pharmaceutical field [7-9]. It has been demonstrated that the positively charged chitosan nanoparticles had strong electrostatic interaction with the negatively charged mucin glycosylation, leading to strong mucosal adhesion. This interaction is responsible for prompting the contact between nanoparticles and epithelial cells and increasing uptake of particles in aggregate lymphoid nodule [10-11]. The objective of this study was to prepare insulinchitosan nanoparticles (ICNS) using ionic crosslinking method. Response surface method was applied to optimize the formulation and analyze the influence of variables on insulin encapsulation efficiency. Some properties of particles such as shape, size, zeta potential and release behavior were analyzed.

\section{EXPERIMENTAL}

\section{Materials}

Chitosan (CS, 400kDa) was obtained from Haixin Biological Product Co., Ltd, China, while insulin (27.5IU. $\mathrm{mg}^{-1}$ ) was purchased from Jiangsu Wangbang Bio-Technology Co., Ltd, China. Trimeric sodium phosphate (TPP) and acetic acid were obtained from Sigma Chemicals, St Louis, USA. All other chemicals purchased were of analytical grade and were used without further purification.

\section{Experimental design}

The ratio between insulin and chitosan $(A), \mathrm{pH}$ of medium $(B)$ and rotation speed $(C)$ were the 3 main effective factors and drug encapsulation efficiency as response surface experimental factors were selected to carry out the experiments. Range of the ratio between insulin and chitosan $(\mathrm{g} / \mathrm{g})$ was $0.05 \sim 0.15, \mathrm{pH}$ of medium was $3.0 \sim 6.0$, rotation speed was $100 \sim$ $300 \mathrm{rpm}$. Box-Behnken central composite design principle was adopted to optimize experimental design and the data analyzed using DesignExpert $^{\circledR}$, version 8.0.6.1 (Stat-Ease Inc, USA) to generate a Box-Behnken matrix design as shown in Table 1. Out of a total test point of 17 obtained, 12 were factorial points while 5 were zero points to evaluate error.

\section{Preparation of ICNS}

CS (50 mg) was dissolved in 1\% (v/v) acetic acid solution, stirring with a magnetic stirrer and swelling over night. Saturated $\mathrm{NaOH}$ solution was used to adjust the $\mathrm{pH}$ of the medium to the exact $\mathrm{pH}$ used. $\mathrm{NaOH}(0.01 \mathrm{~mol} / \mathrm{L})$ solution containing insulin was added with a dropper at 2 $\mathrm{ml} / \mathrm{min}$ into the chitosan solution and stirring continued for $2 \mathrm{~h}$. TPP reserve liquid $(0.5 \mathrm{mg} / \mathrm{mL})$ was prepared and filtered through $0.45 \mu \mathrm{m}$ filter

Table 1: Box-Behnken matrix design scheme and response values

\begin{tabular}{ccccc}
\hline $\begin{array}{c}\text { Fomulation } \\
\text { code }\end{array}$ & A(g/g) & B & C/rpm & Y EE(\%) \\
\hline F1 & 0.10 & 4.50 & 200.00 & $88.0 \pm 3.4$ \\
F2 & 0.10 & 4.50 & 200.00 & $87.6 \pm 5.6$ \\
F3 & 0.10 & 4.50 & 200.00 & $86.9 \pm 4.1$ \\
F4 & 0.10 & 6.00 & 300.00 & $86.5 \pm 3.9$ \\
F5 & 0.10 & 4.50 & 200.00 & $86.8 \pm 6.1$ \\
F6 & 0.15 & 4.50 & 300.00 & $79.8 \pm 5.2$ \\
F7 & 0.15 & 4.50 & 100.00 & $64.7 \pm 3.5$ \\
F8 & 0.05 & 3.00 & 200.00 & $91.5 \pm 4.9$ \\
F9 & 0.05 & 4.50 & 300.00 & $82.5 \pm 4.7$ \\
F10 & 0.05 & 6.00 & 200.00 & $81.9 \pm 3.9$ \\
F11 & 0.15 & 3.00 & 200.00 & $81.2 \pm 5.1$ \\
F12 & 0.15 & 6.00 & 200.00 & $69.9 \pm 3.6$ \\
F13 & 0.10 & 3.00 & 100.00 & $87.8 \pm 4.2$ \\
F14 & 0.10 & 6.00 & 100.00 & $73.4 \pm 3.1$ \\
F15 & 0.10 & 3.00 & 300.00 & $85.6 \pm 5.9$ \\
F16 & 0.05 & 4.50 & 100.00 & $78.7 \pm 4.4$ \\
F17 & 0.10 & 4.50 & 200.00 & $88.3 \pm 5.5$ \\
\hline
\end{tabular}


(Jiuding Inc, China). ICNS were prepared by dropping $3 \mathrm{ml}$ of TPP reserve liquid quickly into the system at $40{ }^{\circ} \mathrm{C}$ and continuously stirred at certain speed ranging from 100 to $300 \mathrm{rpm}$ for 1 $\mathrm{h}$ until the mixture turned creamy. ICNS collected was washed 3 times with deionized water and centrifuged at $16000 \mathrm{rpm}$ for $20 \mathrm{~min}$. The particles were freeze-dreid using vacuum freeze drier (FD-1, Boyikang, China) to obtain the powders.

\section{Characterization of ICNS}

Scanning electron microscopy (S-4800, Hitachi, Japan) was used to observe the morphology of ICNS. Particle size and zeta potential were determined using a Zetasizer (Nano ZS90, Malvern, UK).

\section{Determination of drug encapsulation efficiency}

Dried ICNS $(5 \mathrm{mg}$ ) was dispersed in $10 \mathrm{ml}$ of $0.01 \mathrm{~mol} / \mathrm{L} \mathrm{HCl}$ solution.Ultrasonic extraction was performed for $15 \mathrm{~min}$ at $4{ }^{\circ} \mathrm{C}$. The product obtained was centrifuged at $16000 \mathrm{rpm}$ for 30 min and the supernatant was collected and filtered through a $0.22 \mathrm{~mm}$ millipore filter. The absorbance of the filtrate was taken at $276 \mathrm{~nm}$ using a UV/Visible spectrophotometer (model 1601, Shimadzu, Japan) to determine the amount of insulin trapped in the ICNS. The encapsulation efficiency (EE, \%) was calculated using Eq 1.

$\mathrm{EE}(\%)=\{(\mathrm{Si}-\mathrm{Sf}) / \mathrm{Si}\} 100$

where $\mathrm{Si}$ is the initially added insulin and $\mathrm{Sf}$ is the free insulin in the supernatant,

\section{Investigation of drug release behavior}

The in vitro release profile of insulin from nanoparticles was investigated by determining the residual amount of insulin present in the nanoparticles. Several amount $(2 \mathrm{mg})$ of the same freeze dried ICNS were suspended in tubes with caps filled with $5 \mathrm{ml}$ phosphate buffer $(\mathrm{pH} 7.4)$ at $37^{\circ} \mathrm{C}$ and shaken horizontally at 50 $\mathrm{min}^{-1}$ by using an orbital shaker bath (SHA-C, Kaihang, China). At preselected time intervals, three of tubes were withdrawn and centrifuged at $16000 \mathrm{rpm}$ for $30 \mathrm{~min}$ and the precipitated ICNS was collected and washed 3 times with deionized water. The amount of residual insulin in nanoparticles was analyzed at $276 \mathrm{~nm}$ by using the same method as described in the section of determination of drug encapsulation efficiency. The cumulative amount of insulin (AR) released from ICNS at different time was calculated using Eq 2.

$\operatorname{AR}(\%)=\{(\mathrm{St}-\mathrm{Sr}) / \mathrm{St}\} 100$

where St is the initially trapped insulin and $\mathrm{Sr}$ is the residual insulin in ICNS at various times.

\section{Statistical analysis}

One-way ANOVA was applied to determine significant difference between various values. The level of significance was set at $p<0.05$.

\section{RESULTS}

\section{Response surface ethodology (RSM)}

The encapsulation efficiency of ICNS $(\mathrm{Y})$ ranged from $64.7 \pm 3.5$ to $91.5 \pm 4.9 \%$. RSM results for response $\mathrm{Y}$ (\% encapsulation efficiency) are given in Table 1. The resultant equation for response $\mathrm{Y}$ is shown in Eq 3.

$\mathrm{Y}=+87.52-4.87 \mathrm{~A}-4.30 \mathrm{~B}+3.72 \quad \mathrm{C}-$

$43 A B+2.83 A C+3.82 B C-6.65 A^{2}+0.25 B^{2}-4.45 C^{2}$

The result of regression variance analysis and significance test on the model was investigated. $F$ value is 31.24 and the $p$ value $<0.0001$, which demontrates that the model is highly significant. Model determination coefficient value was 0.9445 , which showed that there was linear relationship between the equation dependent variables and all independent variables. The related influence of three factors classified in response value from high to low was the ratio between insulin and chitosan $(\mathrm{A}), \mathrm{pH}$ of medium (B) and rotation speed (C). Factors that affected the response value remarkably were $A, B, C, A C$, $B C, A^{2}, C^{2}$ and no simple linear relationship was established between the response values and factors. Three factors had a strong interaction on the response value.

The regression optimization response surface plot is shown in Figure 1. The ratio between insulin and chitosan (A) can affect EE. As shown in Figure 1-I, EE value was increased with the increase of the ratio. When the ratio between insulin and chitosan (A) was $0.08 \mathrm{~g} / \mathrm{g}$, maximum EE value was $92.82 \%$. After that, EE value decreased with increase in the ratio. With the decrease of $\mathrm{pH}$ of medium (B), EE value was increased gradually.

\section{Response surface analysis}

Trop J Pharm Res, January 2014;13 (1): 

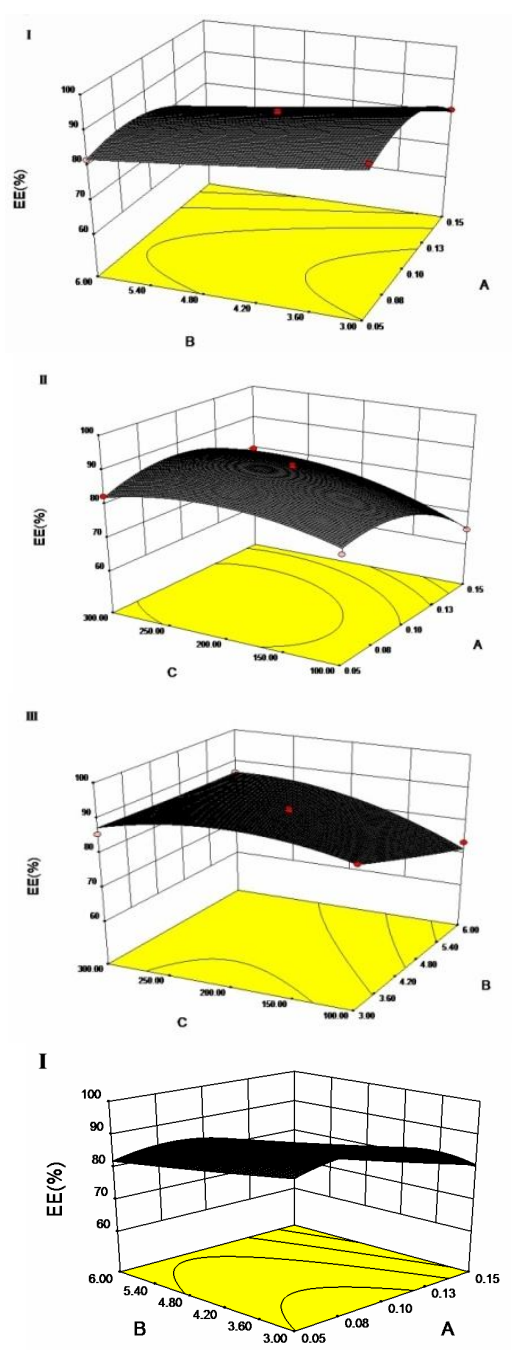

II

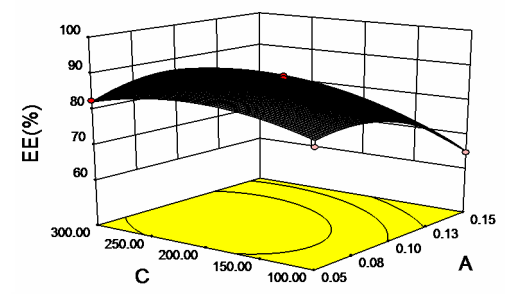

III

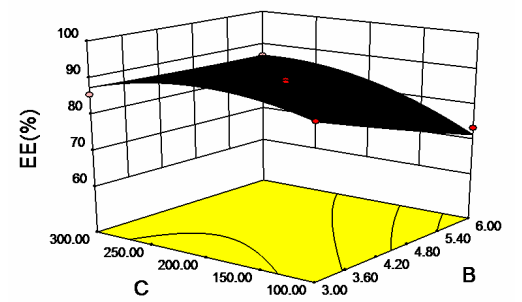

Figure 1: Effect of (I) insulin:chitosan ratio $(A)$ and $\mathrm{pH}$ of medium (B); (II) insulin:chitosan ratio (A) and rotation speed (C); (III) $\mathrm{pH}$ of medium (B) and rotation speed $(C)$ on encapsulation efficiency $(E E)$

The regression optimization response surface plot is shown in Figure 1. The ratio between insulin and chitosan (A) can affect EE. As shown in Figure 1-I, EE value was increased with the increase of the ratio. When the ratio between insulin and chitosan (A) was $0.08 \mathrm{~g} / \mathrm{g}$, maximum EE value was $92.82 \%$. After that, EE value decreased with increase in the ratio. With the decrease of $\mathrm{pH}$ of medium (B), EE value was increased gradually. Flatness of surface suggested that interaction between factors $A$ and $\mathrm{B}$ was weak. As shown in Figure 1 (II), as ratio and rotation speed (C) increased, EE value showed a curved surface. When the ratio was $0.09 \mathrm{~g} / \mathrm{g}$ and rotation speed was $232.46 \mathrm{rpm}$, maximum EE value obtained was $88.85 \%$. The curves displayed a steep slope, indicating that factors $A$ and $C$ had significant interaction $(p<$ 0.05 ). The interaction graph between $\mathrm{pH}$ of medium (B) and rotation speed $(C)$ is shown in Figure 1 (III). Maximum EE (92.07\%) was obtained when $\mathrm{pH}$ and rotation speed were 3 and $198.93 \mathrm{rpm}$, respectively. The sharp slope of the surface implies that the interaction between B and $C$ was significant $(p<0.05)$. The optimal condition for formulation of ICNS was as follows: insulin/chitosan ratio $0.08, \mathrm{pH} 3.0$, and rotation speed $187.4 \mathrm{rpm}$. The highest encapsulation efficiency of $92.88 \%$ was obtained. Verifying experiments were established under the optimal conditions and EE was $93.10 \%$ with low percentage bias (3.78\%).

\section{Morphology of ICNS}

The size range of ICNS was between $91.28 \pm 7.9$ and $220.2 \pm 9.5 \mathrm{~nm}$ and the average zeta potential was $14.4 \pm 2.9 \mathrm{mv}$. It can be seen from Figure 2 that ICNS showed good sphericity with good monodispersity and homogenous particle size distribution.

Figure 3 shows that three ICNS formulations (F1, F8 and F17) prepared using the matrix design and the optimal formulation $\left(\mathrm{F}_{\mathrm{of}}\right)$ exhibited good drug release behavior. More than $16.8 \%$ of total drug was released rapidly in the first $1 \mathrm{~h}$. Thereafter, insulin trapped in ICNS was released into the medium slowly and $>93 \%$ was released completely within $24 \mathrm{~h}$. The in vitro release data were fitted into release kinetics models with the aid of using Origin Version 8.0 to determine the best-fit release model .

The release kinetic data analysis and correlation coefficient $\left(R^{2}\right)$ are shown in Table 2 . The relationship between cumulative release rate and time was tested using Zero-order, First-order, Higuchi and Ritger-Peppas models. For all the foumulations, in vitro drug release was best fitted to Ritger-Peppas modelwhich showed the highest correlation coefficient $\left(R^{2}\right)$. The diffusional exponent $(n)$ in Ritger-Peppas model was greater than 0.45 , which suggests that drug 
release from ICNS was non-Fickian diffusion and therefore was influnced by drug diffusion and matrix erosion [12].

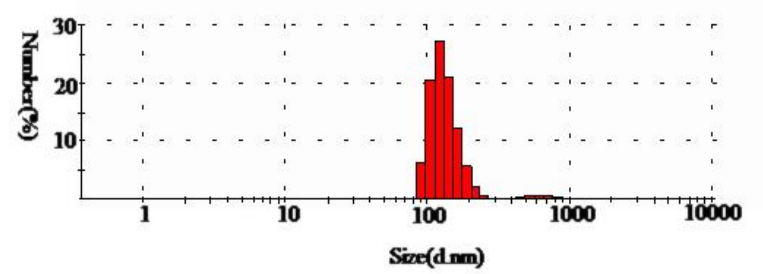

A
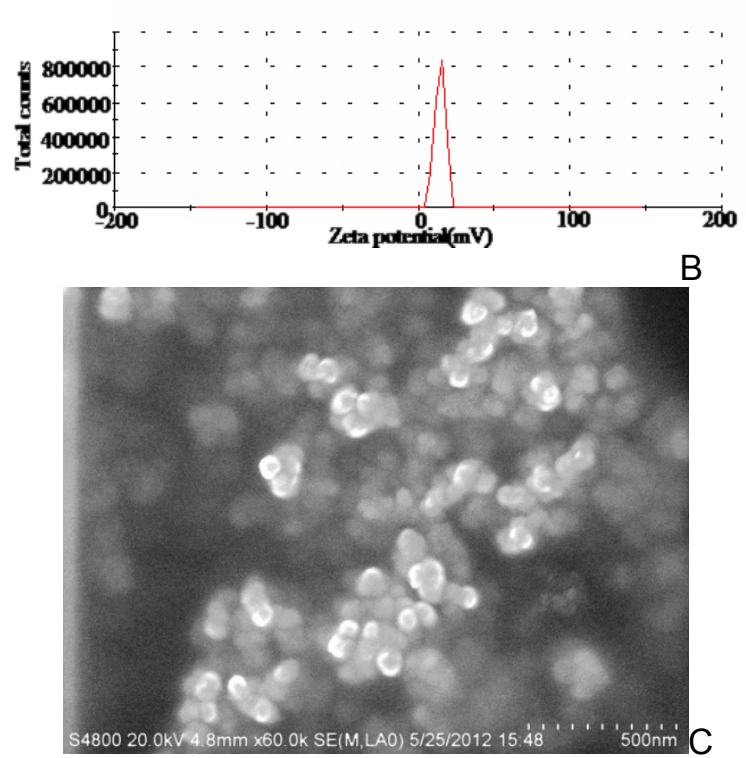

Figure 2: Morphology of ICNS (Note: $A=$ particle distribution of ICNS, B = zeta potential distribution of ICNS, and C = SEM of ICNS)

\section{In vitro drug release}

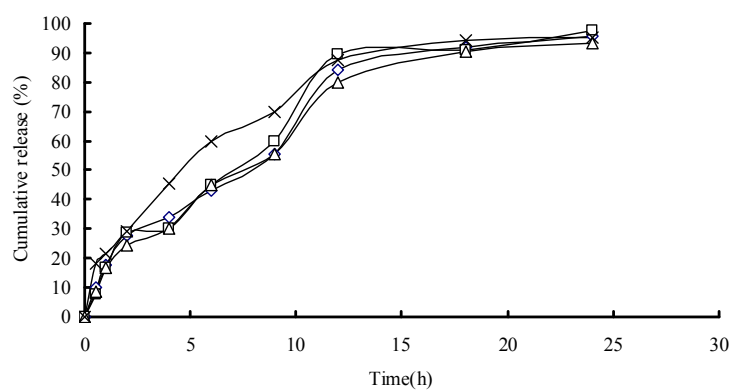

Figure 3: Drug release of ICNS (Note: $\mathrm{F} 1=\Delta$, F8 $=\times$, $\left.F_{\text {of }}=\diamond, F 17=\square\right)(n=3)$

Table 2: Drug-release kinetic data for ICNS

\begin{tabular}{lllll}
\hline Code & $\begin{array}{l}\text { Zero } \\
\text { order }\end{array}$ & $\begin{array}{l}\text { First } \\
\text { order }\end{array}$ & Higuchi & $\begin{array}{l}\text { Ritger- } \\
\text { Peppas }\end{array}$ \\
& R2 & R2 & R2 & R2 n \\
\hline F1 & 0.9091 & 0.9788 & 0.9732 & 0.97940 .6269 \\
F2 & 0.838 & 0.9716 & 0.9700 & 0.98060 .4845 \\
F $_{\text {of }}$ & 0.9024 & 0.9718 & 0.9679 & 0.98190 .5831 \\
F17 & 0.8871 & 0.9557 & 0.9574 & 0.96700 .6350 \\
\hline
\end{tabular}

DISCUSSION
Response surface method was a useful tool to predict formulation and was adopted to establish the function of relation between regression factors and experimental results, finding explicit functions, regression equation on factors and response value through the whole rigion. The highest response value and the optimal formulation were obtianed with good predition $[13,14]$. Using RSM, it is possible to optimize the formulation with optimum drug encapsulation efficiency, good sphericity and homogenous particle size distribution [15]. ICNS showed the rapid drug release during the initial period and more than $16.8 \%$ of total drug were released from ICNS within the first $1 \mathrm{~h}$. This is perhaps due to the fact that free insulin was attached to the surface of ICNS or migrated toward the surface with evaporation of water during the freeze-drying process, leading to rapid dumping from ICNS at the initial stage. Drug release decreased after rapid release was completed. As the formation of a porous structure through the whole ICNS by continuous dissolution and erosion of chitosan continued, drug resistance to dissolution and diffusion reduced, and thus drug release rate increased rapidly.

\section{CONCLUSION}

ICNS prepared showed excellent properties on morphology and also displayed a prolonged drug release within $24 \mathrm{~h}$. It could be a promising carrier for the oral administration of insulin.

\section{ACKNOWLEDGMENT}

Both Liang Zhao and Chang Su contributed equally to the authorship of this manuscript. This work is supported Natural Science Foundation of Liaoning Province (No. 2013010135-401) and Grant of Liaoning Medical University (No. XZJJ20130104-05). The authors thank Dr Rongjian Su (Central Laboratory, Liaoning Medical University) for his help. The authors also wished to acknowledge the support of Prof Wei Cheng and other staff of Pharmacy Department, Liaoning Medical University.

\section{REFERENCES}

1. Cournarie F, Savelli MP, Rosilio V, Bretez F, Vauthier $C$, Grossiord JL, Seiller M. Insulin loaded W/O/W multiple emulsions: comparison of the performances of systems prepared with mediumchain-triglycerides and fish oil. Eur $J$ Pharm Biopharm. 2004; 58: 477-482.

2. Niu M, Lu Y, Hovgaard L, Guan P, Tan Y, Lian R, Qi J, $W u \quad W$. Hypoglycemic activity and oral bioavailability of insulin-loaded liposomes containing bile salts in rats: the effect of cholate type, particle size and administered dose. Eur J 
Pharm Biopharm. 2012; 81(2): 265-272.

3. He $P$, Tang $Z$, Lin L, Deng M, Pang X, Zhuang $X$, Chen $X$. Novel biodegradable and $\mathrm{pH}$-sensitive poly(ester amide) microspheres for oral insulin delivery. Macromol Biosci. 2012; 12(4): 547-556.

4. Zhang ZH, Zhang YL, Zhou JP, LV HX. Solid lipid nanoparticles modified with stearic acidoctaarginine for oral administration of insulin. Int $\mathrm{J}$ Nanomedicine. 2012; 7: 3333-3339

5. Mesiha MS, Sidhom MB, Fasipe B. Oral and subcutaneous absorption of insulin poly(isobutylcyanoacrylate)nanoparticles. Int $\mathrm{J}$ Pharm. 2005; 288: 289-293.

6. Lai SK, Wang YY, Hanes J. Mucus-penetrating nanoparticles for drug and gene delivery to mucosal tissues. Adv Drug Deliv Rev. 2009; 61(2): 158-171.

7. Di Martino A, Sittinger M, Risbud MV. Chitosan: a versatile biopolymer for orthopaedic tissueengineering. Biomaterials. 2005; 26(30): 59835990.

8. Sinha VR, Singla AK, Wadhawan $S$, Kaushik $R$, Kumria $R$, Bansal K, Dhawan S. Chitosan microspheres as a potential carrier for drugs. Int J Pharm. 2004; 274(1-2): 1-33.

9. Grenha A, Grainger CI, Dailey LA, Seijo B, Martin GP, Remuñán-López $\quad C$, Forbes $B$. Chitosan nanoparticles are compatible with respiratory epithelial cells in vitro. Eur J Pharm Sci. 2007; 31(2): 73-84.

10. Valerie $D$, Amin KM, Merw in JR. Effect of chitosan on epithelial permeability and structure. Int $J$ Pharm. 1999; 182: 21- 32.

11. Park JH, Saravanakumar G, Kim K, Kwon IC. Targeted delivery of low molecular drugs using chitosan and its derivatives. Adv Drug Deliv Rev. 2010; 62(1): 28-41.

12. Ritger RL, Peppas NA. A simple equation for description of solute release. I. Fickian and nonFickian release from non-swellable devices in the form of slabs, spheres, cylinders or discs. $J$ Controlled Release. 1987; 5(1): 23-36.

13. Sharma S, Malik A, Satya S. Application of response surface methodology (RSM) for optimization of nutrient supplementation for $\mathrm{Cr}$ (VI) removal by Aspergillus lentulus AML05. J Hazard Mater. 2009; 164(2-3): 1198-1204.

14. Bezerra MA, Santelli RE, Oliveira EP, Villar LS, Escaleira LA. Response surface methodology (RSM) as a tool for optimization in analytical chemistry. Talanta. 2008; 76(5): 965-977.

15. Shahzad MK, Ubaid M, Murtaza G. Formulation and Optimization of Celecoxib-Loaded Microspheres Using Response Surface Methodology. Trop J Pharm Res. 2012; 11(5): 695-702. 